\title{
Analysis of Extreme Maternal Morbidity at the Women's Hospital of Aguascalientes
}

Mayela G. Cuesta-Galindo ${ }^{1}$, Daniel E. Bravo-Aguirre ${ }^{1}$, Francisco J. Serna-Vela ${ }^{2}$, Omar O. CamarilloContreras ${ }^{1}$, José de Jesús O. Yañez-Torres ${ }^{3}$, María del Consuelo Robles-Martínez ${ }^{1}$, Alejandro RosasCabral $^{4}$

1. Gynecology and Obstetrics Department, Women's Hospital of Aguascalientes, Aguascalientes, MEX 2. Investigation Department, Health Services Institute of the State of Aguascalientes, Aguascalientes, MEX 3. Gynecology and Obstetrics Department, Women's Hospital of Aguascalientes, Aguascalientes, MEX 4. Medicine Department, Autonomous University of Aguascalientes, Aguascalientes, MEX

Corresponding author: Alejandro Rosas-Cabral ,drrosascabral@gmail.com

\section{Abstract \\ Background}

Extreme maternal morbidity is defined as "events that potentially threaten the life of a pregnant woman during pregnancy, childbirth or the puerperium, but that due to a medical intervention the patient does not die", and this is an indicator of health quality at the hospital and demographic level.

\section{Objective}

The aim of this study was to determine the prevalence of extreme maternal morbidity in the Women's Hospital of Aguascalientes, Mexico.

\section{Material and methods}

A retrospective cross-sectional study was conducted under the criteria of the World Health Organization and the Latin American Federation of Obstetrics and Gynecology Societies for the definition of extreme maternal morbidity to determine the prevalence of near miss morbidity, between January 1 and December 31, 2016.

\section{Results}

We found 165 cases of extreme maternal morbidity; no maternal death was registered during the study year. The extreme maternal morbidity rate was 0.016 and 16.69 per 1000 live births; the ratio of extreme maternal morbidity cases / obstetric admissions was 11.07 . The prevalence of extreme maternal morbidity was $1.6 \%$. The main causes of extreme maternal morbidity were hypertensive disorders (57\%), obstetric hemorrhage (29\%), sepsis (1\%) and other (13\%).

Review began 05/20/2021 Review ended 06/23/2021 Published 07/03/2021

(c) Copyright 2021

Cuesta-Galindo et al. This is an open access article distributed under the terms of the Creative Commons Attribution License CC-BY 4.0., which permits unrestricted use, distribution, and reproduction in any medium, provided the original author and source are credited.

\section{Conclusion}

Extreme maternal morbidity in our institution had a similar prevalence to that reported in other countries and was mainly caused by hypertensive disorders.

Categories: Family/General Practice, Obstetrics/Gynecology, Epidemiology/Public Health

Keywords: maternal near miss, extreme maternal morbidity, maternal mortality, obstetrics, hypertensive disorders

\section{Introduction}

Maternal Mortality is an indicator of the level of economic development of a given country, of the reach of its health infrastructure and the level of inequality of such [1].

In order to learn about the behavior of maternal death, different approaches have been developed, such as "verbal autopsy" or extreme maternal morbidity (near miss) [2]. The World Health Organization (WHO) defines extreme maternal morbidity as an event that potentially threatens the life of a pregnant woman, be it during the pregnancy, childbirth or within the following 42 days after the end of the pregnancy itself, but, thanks to a medical intervention, the woman does not die [3].

Extreme maternal morbidity rate is also related to the level of development of a given region. In 2014, maternal morbidity rates of $4.9 \%$ were reported in Latin America, $5.1 \%$ in Asia, $14.9 \%$ in Africa, $1.4 \%$ in North America and $0.8 \%$ in Europe [4]. Depending on the context and criteria used, the incidence of extreme maternal morbidity varies between $0.6 \%$ and over $30 \%$ [5].

The progression of normality to maternal morbidity is related to the type of event, social factors, 
demographic circumstances (regions of difficult access for treatment), characteristics of the service provider (tardy diagnosis of morbidity and/or delay regarding the initiating of treatment), supplies available in health institutions and the patient's attitude towards the system (inadequate prenatal control, not recognizing alarm data and/or not requesting timely medical attention) [6]. Approximately 50 million maternal health problems are reported around the world every year and almost 300 million women suffer, in short and long term, of illnesses and lesions related to pregnancy, childbirth and puerperium [7]

Amongst the Millennium Development Objectives, as a world effort, is that to improve maternal health as a part of a global Alliance for development, it being one of the most urgent human needs and one of the fundamental rights of all human beings. [8]

The study of extreme maternal morbidity may be an indicator to complete the analysis of maternal deaths with the intention of evaluating health services and the reach of sanitary and assistance infrastructure [9]. Knowing the physiopathology of each condition, the evaluation of the patients' characteristics, medical attention they received and the follow-up of conditions of those who survived will allow that information to be used to determine the factors contributing to maternal morbidity, thus helping to establish prompt prophylactic and strategic measures that will allow the decrease in complications and sequels in short and long terms, achieving a real impact in avoiding new cases of maternal deaths, at local, regional and national levels. Thus, the objective of this study is to determine the prevalence of extreme maternal morbidity at the Women's Hospital of Aguascalientes in the period from January 1st to December 31, 2016.

\section{Materials And Methods}

A retrospective cross-sectional study was conducted, where files from the obstetric intensive care unit of the Women's Hospital of Aguascalientes were reviewed in order to identify women who met the criteria of Extreme Maternal Morbidity established by the World Health Organization (WHO), and the Latin American Federation of Obstetrics and Gynecology Societies (FLASOG), between January 1st and December 31, 2016. Sampling was not conducted since it was possible to study the total population.

Population was divided in three categories (specific illness, organ/system failure or malfunction and established management) according to the presence of one or more criteria from the WHO/FLASOG (Table 1). Some of the patients complied with the characteristics to be included in more than one category, thus, having more than one variable of each category. 


\section{Cureus}

Criteria related to the specific illness

Pre-eclampsia Systolic blood pressure $\geq 160 \mathrm{mmHg}$ or diastolic blood pressure $\geq 110 \mathrm{~mm} \mathrm{Hg}$, platelets $<100,000$. Duplicate liver enzymes, with severity persistent epigastralgia with no explanation, creatinine $>1.1 \mathrm{mg} / \mathrm{dL}$ or duplication in absence of renal illness, pulmonary edema data or neurological or visual alterations

Eclampsia Generalized convulsions, coma or both in absence of other neurological disorder

Hypovolemic Secondary syndrome to acute loss of circulating volume. Clinical data: arterial hypotension, tachycardia, oliguria, deterioration shock in the state of consciousness, paleness, distal hypothermia and delayed capillary refilling pressure $<60 \mathrm{~mm} \mathrm{Hg})$, fever $\left(38^{\circ} \mathrm{C}\right)$, hypothermia $\left(<36^{\circ} \mathrm{C}\right)$, tachypnea $(>20)$, tachycardia $(>90)$ leukocytes $>12,000$ or $<4,000$ or $>10 \%$ of bands

Criteria related to organ/system failure or malfunction

Heart Heart arrest, pulmonary edema with intravenous diuretic use, inotropic, vasopressor o vasodilator support.

Absent peripheral pulse or hypotension for 30 minutes associated to hypovolemic or septic shock, median arterial pressure $<60$
Vascular
$\mathrm{mm} \mathrm{Hg}$, capillary refilling $>2$ seconds, need of vasoactive support. Also consider where blood arterial pressure $>160 \mathrm{~mm}$ Hg or diastolic arterial pressure $>110 \mathrm{~mm} \mathrm{Hg}$ persisting for more 20 minutes.

Acute deterioration of renal function, $50 \%$ creatinine increase in 24 hours or elevation $>1.2 \mathrm{mg} / \mathrm{dL}$, oliguria $(<0.5 \mathrm{ml} / \mathrm{kg} / \mathrm{hour})$ not responding to intravenous liquid replacement and intravenous diuretics, acid-base or electrolytic disorder

Liver Skin and scleral jaundice, or total bilirubin $>3 \mathrm{mg} / \mathrm{dL}$, transaminase $>70 \mathrm{UI} / \mathrm{dL}$, lactic dehydrogenase $>600 \mathrm{UI} / \mathrm{L}$

Metabolical Joint comorbidities such as diabetic ketoacidosis, thyroid crisis, that may manifest as part of alterations of the underlying illness, lactic hyperlactacidemia $>200 \mathrm{mmol} / \mathrm{L}$, or hyperglycemia $>240 \mathrm{mg} / \mathrm{dL}$ not having diabetes

Cerebral Coma, convulsions, confusion, disorientation in person, space or time, focalization signs, hemorrhagic or ischemic lesions.

Respiratory Respiratory failure syndrome, need of invasive or non-invasive ventilatory support, respiratory arrest

Disseminate intravascular coagulation, (prolonged coagulation time, fibrinogen decreased, D-Dimer elevation) platelets $<100,000 / \mathrm{mm} 3$, Lactic dehydrogenase $>600 \mathrm{UI} / \mathrm{L}$

Criteria Related to established treatment

Admittance to

obstetric Patient who enters due to the need to administer amines, or mechanic ventilation, intubation and advance cardiopulmonary intensive unit resuscitation, do not count as criteria for patient who enter to elective hemodynamic stabilization

care

Surgery

Procedures practiced with urgency for management of obstetrics complications or for any condition which generates a serious compromise of the pregnant woman; procedures different to curettage, delivery or cesarean.

Transfusion Transfusion of 3 or more units of any blood component facing an acute event

\section{TABLE 1: Criteria to identify cases of Extreme Maternal Morbidity according to WHO /FLASOG} classification.

The study was approved by the Ethical Research Committee of the State of Aguascalientes, obtaining a registry based on the criteria for the identification of extreme maternal morbidity cases. According to criteria from WHO/FLASOG, variables were added to obtain information on characteristics regarding sociodemographic and obstetric histories of each of the participants in the study.

For the statistical analysis, data were entered and analyzed using the SPSS program version 21.0 (IBM Corp. Armonk, NY), frequencies and percentages were calculated for categorical variables, Chi square was used for the comparison of proportions and a $p$-value of $<0.05$ was considered statistically significant; mean and standard deviation was calculated for continuous variables. The outcome indicators were calculated using the formulas:

Extreme maternal morbidity ratio $=$ Number of extreme maternal morbidity cases $/$ total number of live births $\mathrm{x} 1000$

Ratio of cases of extreme maternal morbidity/ obstetric admissions = Total cases of extreme maternal 


\section{Cureus}

morbidity/ number of obstetric admissions x 1000.

Ratio of maternal deaths per 1000 live births = Number of maternal deaths cases $/$ total number of live births $\mathrm{x} 1000$

\section{Results}

During the study period, a total of 14,901 pregnant women were attended in our hospital, and 9,882 births were recorded, of which, 6,331 were eutocic deliveries (64.0\%), 109 were dystocic deliveries (1.1\%), 3,442 (34.9\%) were cesarean sections and 953 were abortions.

One hundred sixty six cases of extreme maternal morbidity were identified, and 165 files were analyzed (an incomplete file was excluded); no maternal death was registered during the year of study.

The average age of patients was that of $25.13 \pm 6.56$ with a range between 14 and 46 years of age; $85 \%$ of patients with extreme maternal morbidity were 34 years of age or younger. Other socio-demographic characteristics of patients may be observed in Table 2 .

\begin{tabular}{|c|c|}
\hline Characteristic & Number (\%) \\
\hline Age (years, average, standard deviation, range) & $25.13 \pm 6.56(14-46)$ \\
\hline 14-19 & $26 \%(42)$ \\
\hline $20-34$ & $59 \%(98)$ \\
\hline$>35$ & $15 \%(25)$ \\
\hline \multicolumn{2}{|l|}{ Level of Studies } \\
\hline Primary & $19 \%(31)$ \\
\hline Secondary & $56 \%(93)$ \\
\hline Technical Career & $2 \%(4)$ \\
\hline High school & $17 \%(28)$ \\
\hline Bachelor's Degree & $4 \%(7)$ \\
\hline Postgraduate & $1 \%(1)$ \\
\hline Illiterate & $1 \%(1)$ \\
\hline \multicolumn{2}{|l|}{ Marital Status } \\
\hline Cohabitation & $55 \%(90)$ \\
\hline Married & $23 \%$ (39) \\
\hline Single & $21 \%(35)$ \\
\hline Separated & $1 \%(1)$ \\
\hline \multicolumn{2}{|l|}{ Occupation } \\
\hline Housewife & $84 \%(138)$ \\
\hline Employee & $6 \%(10)$ \\
\hline Student & $5 \%(8)$ \\
\hline Merchant & $4 \%(7)$ \\
\hline Professional & $1 \%(2)$ \\
\hline
\end{tabular}

TABLE 2: Socio-Demographic characteristics of 165 cases of extreme maternal morbidity at the Women's Hospital of Aguascalientes from January 1st to December 31st, 2016. 


\section{Cureus}

were primiparous (66), $39 \%$ (64) with 3 or more pregnancies and $21 \%$ (35) on their second pregnancy $\left(X^{2}=0.05, \mathrm{p}=0.9\right)$

Regarding prenatal control, the number of medical consultations varied between 0 and 19 , with an average of 5 consultations, within that established in the Official Mexican Norm; 40\% (66), initiated prenatal control previous to the 12 weeks into pregnancy and 60\% (99) received medical prenatal consultation in a tardy fashion. According to the type of prenatal control, 59\% (97) of the patients received optimal prenatal control (equal or higher to 5 consultations), 36\% (60) sub-optimal (1-4 consultations) and 5\% (8) denied having received any prenatal control attention (Table 3).

\begin{tabular}{|c|c|c|}
\hline Number of Consultations & $\mathbf{N}$ & $\%$ \\
\hline$\geq 5$ consultations & 97 & 59 \\
\hline 1 -4 consultations & 60 & 36 \\
\hline None consultations & 8 & 5 \\
\hline Total & 165 & 100 \\
\hline
\end{tabular}

\section{TABLE 3: Number of prenatal consultations in 165 cases of extreme maternal morbidity at the} Women's Hospital of Aguascalientes

Gestational age at the end of pregnancy had a mean of 33 weeks, varying between 5 to 42 weeks. Of these, $44 \%$ (72) were resolved at maturity, 39\% (64) were premature, 6\% (10) at fetal immaturity, $7 \%$ (12) were not viable or within the first trimester and $4 \%$ (7) continued pregnancy after the event.

The indication to end of pregnancy was reported in the following order: hypertensive disorders 53\% (87), spontaneous labor $18 \%$ (30), placental alterations 14\% (23), iterative $13 \%$ (22), and other causes $2 \%$ (3).

As to the means of interruption of pregnancy, the most used was cesarean with $71 \%$ (117), natural deliveries $18 \%$ (30), laparotomy due to ectopic pregnancy $4 \%$ (7), uterine curettage evacuation 3\% (4), and pregnancies not concluded at $4 \%$ (7). $72 \%$ (119) of the patients were healthy at the moment of the event and $28 \%(46)$ presented a previous co-morbidity.

Regarding the perinatal result, 78\% (127) were live products, 6\% (8) stillborn, followed by 4\% (7) with ruptured ectopic pregnancy and 2\% (4) abortions; also registered were 3\% (6) of early neonatal deaths and another 3\% (6) of late neonatal deaths. Of the total of the cases in the study, 4\% (7) continued with the remaining pregnancy having received medical treatment and overcoming the extreme maternal morbidity scenario; no maternal deaths were registered.

The extreme maternal morbidity ratio was 16.69 per 1,000 live births, the relation of cases of extreme maternal morbidity/ obstetric admissions was that of 11.07 , and the prevalence of extreme maternal morbidity was that of $1.6 \%$. (Table 4 ) 


\section{Cureus}

\section{Parameter}

Number of live births

Number of maternal deaths

Number of maternal near-miss cases identified

Regarding the diagnosis, we looked for diseases related to pregnancy, delivery and puerperium linked to a direct or indirect cause of obstetric morbidity. Of these, $87 \%$ (144) were due to a directa cause and $13 \%$ (21) were related to an indirect cause. Direct causes were distributed as follows: hypertensive disorders $57 \%$ (94), obstetric hemorrhage $29 \%$ (48), obstetric sepsis $1 \%$ (2). Of the cases due to an indirect cause, $12 \%$ (19) correspond to other complicated illnesses in pregnancy (diabetic ketoacidosis, thyroid crisis, congenital heart disease, acute pulmonary edema, pulmonary hypertension, pancreatitis, epilepsy, among others) and $1 \%$ (2) included autoimmune/ hematological pathology (Table 5)

\begin{tabular}{|l|c|}
\hline Cause & N (\%) \\
\hline Direct cause & \\
\hline Hipertensive disorders & $94(57)$ \\
Obstetric hemorraghe & $48(29)$ \\
\hline Sepsis & $2(1)$ \\
Indirect cause & $21(13)$ \\
\hline Total & $165(100)$ \\
\hline
\end{tabular}

TABLE 5: Extreme maternal morbidity causes among 165 women admitted in the Women's Hospital of Aguascalientes from January 1st to December 31, 2016

According to WHO/FLASOG criteria, 351 records were included in the 165 patients, of which, 146 (41.5\%) corresponded to specific illness, 147 (41.8\%) to organic failure or dysfunction and 58 (16.3\%) to established management. According to specific illness, the main pathology registered was preeclampsia with severity criteria 58.8\% (86), hypovolemic shock 32.8\% (48), eclampsia 5\% (7), HELLP (hemolysis, elevated liver enzymes, low platelet count) syndrome $0.7 \%(1)$, septic shock $1.4 \%(2)$, and $1.4 \%(2)$ an indirect cause.

Related to organic failure or dysfunction: 147 met criteria related with organ or system failure or dysfunction; $30 \%$ (45) at vascular level, renal 19\% (28), coagulation 15\% (23), hepatic failure 12\% (17), alterations at cerebral level 9\% (13), metabolic dysfunction 7\% (10), respiratory dysfunction 5\% (7) and cardiac failure $3 \%(4)$.

Related to established management, 58 complied with criteria to classify depending on the established management: $62 \%$ (36) required blood transfusion, $26 \%$ (15) required additional surgery, and $12 \%$ (7) needed admission to the intensive care unit; three required intubation or assisted mechanical ventilation, three required administration of vasoactive amines and one required both procedures.

Of the patients studied, 66\% (109) required other procedures to manage their severity and pathology, 52\% (57) with anticonvulsant prophylaxis, 32\% (35) continuous intravenous administration of antihypertensive, $12 \%$ (13) required uterotonics for active management of obstetric hemorrhage and for $4 \%$ (4) it was 
All the patients studied were sent to intensive care in an elective fashion for hemodynamic stabilization, with an average stay of 3 days, varying between 1 and 9 days. Total hospitalization stay was on average of 6 days, with a range of 1 to 15 days.

\section{Discussion}

According to estimates by the WHO, maternal complications during pregnancy, childbirth and puerperium appear even in $15 \%$ of all pregnancies [10]. Extreme obstetric morbidity is considered an instrument to evaluate the level in quality of medical attention. Documenting of extreme maternal morbidity using "near miss" criteria by the WHO has gained acceptance as a valuable tool for documenting the quality of attention given to pregnant women in a certain region or country since it allows for the understanding of factors that contribute to a fatal maternal outcome [11]. In this study, we found a prevalence of 16.69 cases per 1000 live births, which is a value found within the range of prevalence recently reported in a systematic revision published by Abdollahpuor et al. [12], who observed that the pondered prevalence of global extreme maternal morbidity was that of 18.67 cases per 1000 live births, with an Confidence Interval (CI) of 95\% from 16.28 to 21.06. Nevertheless, it is superior to that reported in Brazil and South America (8.69/1000 live births and 11.57/1000 live births respectively), which are countries with a development level similar to that of our country. Likewise, this rate is way superior to that observed in Europe (3.10/1000 live births), but inferior to that observed in India (28.22/1000 live births) or Africa (31.88/1000 live births), which translates the need to reinforce strategies that have been implemented in our country in order to decrease extreme maternal morbidity [13].

$75 \%$ of our patients with a "near miss" event reported a level of education of secondary school or less and only $24 \%$ of them refer a high school or university education, which could mean that, in our population, a low education level is a risk factor for a severe pregnancy complication or a high risk of maternal mortality, which coincides with that stated by Monroy et al. in our country [6], by Dessalegn et al. in Ethiopia [14], and by Benimana et al. in Rwanda [15].

A total of $71 \%$ of our population required delivery by abdominal delivery, which is related to the severity of the maternal morbidity and linked to the fact that cervix conditions of those patients are not favorable for inducing labor. It is nevertheless worth mentioning that some authors have stated that the fact of conducting a cesarean is a risk factor for complications to present themselves leading to "near miss" events, mostly in regions where an important increase in the rate of cesarean procedures has been observed [16].

In the review of the main causes of extreme maternal morbidity, we found hypertensive disorders in first place with $57 \%$ followed by obstetric hemorrhage with $29 \%$, which coincides with that reported by other authors in Latin America [17] and Morocco [18], although it is worth mentioning that it is different to that reported by other authors who mention as a first cause of extreme maternal morbidity to be obstetric hemorrhage [19-22]. This coincides with the high incidence of pre-eclampsia in our country along with the fact that in our study, no maternal deaths were registered, and demonstrates that even though morbidity due to this pathology has not decreased, the established management in our hospital has had an impact on reducing the rate of maternal deaths and reinforces the need to maintain close surveillance of these patients (Table 6).

\begin{tabular}{|c|c|c|c|c|c|c|}
\hline Parameter & 2011 & 2012 & 2013 & 2014 & 2015 & 2016 \\
\hline Number of Live births & 10291 & 10767 & 10741 & 10799 & 10063 & 9882 \\
\hline Number of Maternal deaths & 2 & 7 & 1 & 1 & 1 & 0 \\
\hline Maternal mortality ratio per 1000 live births & 0.19 & 0.65 & 0.09 & 0.09 & 0.09 & \\
\hline
\end{tabular}

TABLE 6: Maternal mortality rates in the Women's Hospital of Aguascalientes from 2011 to 2016

Using criteria established by the WHO, $89 \%$ was categorized as organ or system failure or dysfunction, $88 \%$ as specific illness and $35 \%$ was related to established management, which is different to that reported by Witteveen et al. who refer a frequency of $87.2 \%$ for specific illness criteria, $78.9 \%$ for those related to established management and $38.2 \%$ for criteria based on organ or system dysfunction in a study that compares these criteria in countries with high and low incomes [23]. This indicates that in our institution, "near miss" events are more frequent due to conditions pertaining to the patients rather than faults in treatment.

A total of $59 \%$ of our patients had an optimal prenatal control according to the Official Mexican Norm 
regarding medical attention for pregnant women (NOM-007-SSA2-2016)[24], which coincides to that reported by Shen et al. who state that patients that had less than six medical consultations for prenatal control have a greater risk of presenting a "near miss" event (6.76 Confidence interval 95\%,0.87 a 21.8) [25], which in turn coincides with the average number of prenatal consultations considered as an optimal prenatal control in our country (5 consultations). It is worth mentioning that the initiation of prenatal control of our patients was tardy, implying the risk for development of "near miss" events. Therefore, criteria must be revised regarding the consideration of optimal prenatal control in our country which only considers the number of control consultations during pregnancy and not the timeliness of initiation of such control.

Another individual determinant for obstetric risk to consider is parity. Most authors suggest that multiparity is a risk factor for extreme maternal morbidity [26-28]. Although, there are authors who state that first time pregnancy is also a risk factor associated with this condition [29], we found no significant difference between history of being multiparous and primiparous for the development of an extreme maternal morbidity event $\left(X^{2}=0.05, \mathrm{p}=0.9\right)$.

An important challenge to reduce maternal deaths is that of limited access to emergency obstetric services. Therefore, for adequate care of patients with extreme maternal morbidity, it is of utmost importance to have intensive and intermediate care units. Even though the number of ICUs has been increased, they are not adequately managed for critical obstetric conditions even in developed countries. There are studies that demonstrate that the use of ICUs in women with severe complications protects and reduces maternal mortality but this is not valid for women with less severe conditions. It is not enough to "provide intensive care to any woman with a complication, it is better to clearly judge the use of resources or well established criteria regarding the use of an ICU for obstetric patients at general hospitals to guarantee that the Unit is available for whom needs it the most" [30, 31]. The lack of obstetric ICUs may increase the maternal mortality rate because patients will be treated in non-adequate areas, without trained personnel to control the event, such as recovery wards, rooms for isolated patients, and sometimes, common areas due to lack of physical space in critical areas. It is necessary that all hospital units that attend to obstetric patients have specific physical, technological and human resources infrastructures for the attention of extreme maternal morbidity events. In our institution, all patients were taken to this area, from elective hemodynamic stabilization to the management of severe complications or pre-surgical stabilization, which helps to keep a low maternal mortality rate, even though the rate of extreme maternal morbidity events is still high with respect to rates of other institutions and regions of the world [12]. Availability and appropriate use of good quality ICUs are crucial for the reduction of maternal mortality.

The limitations of our study are it being retrospective and limited to only one center, the brief period of study and thus, a low number of patients included. Nevertheless, it represents the experience of the institution with the larger infrastructure and work load in this region of our country.

\section{Conclusions}

Extreme maternal morbidity still affects a high number of patients that seek medical attention at the Women 's Hospital of Aguascalientes. Hypertensive disorders are the main cause for their state of health to be altered and this is significantly related to the morbidity severity of obstetric patients in our country. These elevated morbidity rates, along with a low maternal mortality rate make it necessary to evaluate the availability and appropriate use of intensive care units in hospitals that provide attention for pregnant women in our state, region and country.

\section{Additional Information}

\section{Disclosures}

Human subjects: Consent was obtained or waived by all participants in this study. Comité Estatal de Investigación en Salud del Instituto de Servicios de Salud del Estado de Aguascalientes issued approval 29 ISSES-29/16. Animal subjects: All authors have confirmed that this study did not involve animal subjects or tissue. Conflicts of interest: In compliance with the ICMJE uniform disclosure form, all authors declare the following: Payment/services info: All authors have declared that no financial support was received from any organization for the submitted work. Financial relationships: All authors have declared that they have no financial relationships at present or within the previous three years with any organizations that might have an interest in the submitted work. Other relationships: All authors have declared that there are no other relationships or activities that could appear to have influenced the submitted work.

\section{References}

1. Rodriguez-Aguilar R: Maternal mortality in Mexico, beyond millenial development objectives: An ageperiod-cohort-model. Plos One. 2018, 13:0194707. 10.1371/journal.pone.0194607

2. Rangel-Flores Y, Martínez-Ledezma A: Research on near-miss maternal mortality in Latin America . Rev Peru Med Exp Salud Publica. 2017, 34:505-11. 10.17843/rpmesp.2017.343.2792

3. Say L, Souza JP, Pattinson RC: Maternal near miss-towards a standard tool for monitoring quality of maternal health care. Best Pract Res Clin Obstet Gynaecol. 2009, 23:287-96. 10.1016/j.bpobgyn.2009.01.007

4. Tunçalp O, Hindin MJ, Souza JP, Chou D, Say L: The prevalence of maternal near miss: a systematic review . 
BJOG. 2012, 119:653-61. 10.1111/j.1471-0528.2012.03294.x

5. Kaye DK, Kakaire O, Osinde MO: Systematic review of the magnitude and case fatality ratio for severe maternal morbidity in sub-Saharan Africa between 1995 and 2010. BMC Pregnancy Childbirth. 2011, 11:65. 10.1186/1471-2393-11-65

6. Monroy AMM, Becerril GET, Vargas AG: Morbilidad materna extrema (near miss) y muertes maternas . Arch Inv Mat Inf. 2012, IV ::146-53.

7. Geller SE, Rosenberg D, Cox SM, Brown ML, Simonson L, Driscoll CA, Kilpatrick SJ: The continuum of maternal morbidity and mortality: factors associated with severity. Am J Obstet Gynecol. 2004, 191:939-44. 10.1016/j.ajog.2004.05.099

8. Morales Andrade E, Ayala Hernandez MI, Morales Valerdi HF, Astorga Castañeda M, Castro Herrera GA: Epidemiología de la muerte materna en México y el cumplimiento del Objetivo 5 del Desarrollo del Milenio, hacia los objetivos del desarrollo sostenible. Rev Esp Med Quir. 2018, 23:64-86.

9. Jahan S, Begum K, Shaheen N, Khandokar M: Near-Miss/Severe acute maternal morbidity (SAMM): a new concept in maternal care. J Bangl Coll Phys Surg. 2006, 24:29-33. 10.3329/jbcps.v24i1.143

10. Calvo-Aguilar O, Morales-García VE, Fabián-Fabián J: Extreme maternal morbidity in the Hospital General Dr. Aurelio Valdivieso, Oaxaca Health Services. Ginecol Obstet Mex. 2010, 78:660-668.

11. Jayaratnam S, Kua S, deCosta C, Franklin R: Maternal 'near miss' collection at an Australian tertiary maternity hospital. BMC Pregnancy Childbirth. 2018, 18:221. 10.1186/s12884-018-1862-6

12. Abdollahpour S, Heidarian Miri H, Khadivzadeh T: The global prevalence of maternal near miss: a systematic review and meta-analysis. Health Promot Perspect. 2019, 9:255-62. 10.15171/hpp.2019.35

13. Franco-Yañez CE, Hernández-Pacheco JA: Monitoring of extreme maternal morbidity (near miss) as an international commitment to complement the quality of attention in maternal healthcare. Perinatol Reprod Hum. 2016, 30:31-38. 10.1016/j.rprh.2016.03.004

14. Dessalegn FN, Astawesegn FH, Hankalo NC: Factors associated with maternal near miss among women admitted in West Arsi Zone Public Hospitals, Ethiopia: unmatched case-control study. J Pregnancy. 2020, 2020:6029160. 10.1155/2020/6029160

15. Benimana C, Small M, Rulisa S: Preventability of maternal near miss and mortality in Rwanda: A case series from the University Teaching Hospital of Kigali (CHUK). PLoS One. 2018, 13:e0195711. 10.1371/journal.pone.0195711

16. Litorp H, Kidanto HL, Rööst M, Abeid M, Nyström L, Essén B: Maternal near-miss and death and their association with caesarean section complications: a cross-sectional study at a university hospital and a regional hospital in Tanzania. BMC Pregnancy Childbirth. 2014, 14:244. 10.1186/1471-2393-14-244

17. Abalos E, Cuesta C, Carroli G, et al.: Pre-eclampsia, eclampsia and adverse maternal and perinatal outcomes: a secondary analysis of the World Health Organization Multicountry Survey on Maternal and Newborn Health. BJOG. 2014, 121 Suppl 1:14-24. 10.1111/1471-0528.12629

18. Assarag B, Dujardin B, Delamou A, Meski FZ, De Brouwere V: Determinants of maternal near-miss in Morocco: too late, too far, too sloppy?. PLoS One. 2015, 10:e0116675. 10.1371/journal.pone.0116675

19. Maswime S, Buchmann E: A systematic review of maternal near miss and mortality due to postpartum hemorrhage. Int J Gynaecol Obstet. 2017, 137:1-7. 10.1002/ijgo.12096

20. Adeniran AS, Ocheke AN, Nwachukwu D, et al.: Non-obstetric causes of severe maternal complications: a secondary analysis of the Nigeria Near-miss and Maternal Death Survey. BJOG. 2019, 126 Suppl 3:41-8. 10.1111/1471-0528.15623

21. Khan T, Laul P, Laul A, Ramzan M: Prognostic factors of maternal near miss events and maternal deaths in a tertiary healthcare facility in India. Int J Gynaecol Obstet. 2017, 138:171-6. 10.1002/ijgo.12208

22. Heemelaar S, Kabongo L, Ithindi T, et al.: Measuring maternal near-miss in a middle-income country: assessing the use of WHO and sub-Saharan Africa maternal near-miss criteria in Namibia. Glob Health Action. 2019, 12:1646036. 10.1080/16549716.2019.1646036

23. Witteveen T, Bezstarosti H, de Koning I, Nelissen E, Bloemenkamp KW, van Roosmalen J, van den Akker T: Validating the WHO maternal near miss tool: comparing high- and low-resource settings . BMC Pregnancy Childbirth. 2017, 17:194. 10.1186/s12884-017-1370-0

24. NOM-007-SSA2-2016. Norma Oficial Mexicana para la atención de la mujer durante el embarazo . (2016). Accessed: July 7, 2021: https://siteal.iiep.unesco.org/pt/node/3562.

25. Shen FR, Liu M, Zhang X, Yang W, Chen YG: Factors associated with maternal near-miss morbidity and mortality in Kowloon Hospital, Suzhou, China. Int J Gynaecol Obstet. 2013, 123:64-7. 10.1016/j.ijgo.2013.06.011

26. Nava ML, Urdaneta JR, González ME, et al.: Caracterización de la paciente obstétrica críticamente enferma, experiencia de la maternidad “Dr. Armando Castillo Plaza”. Maracaibo, Venezuela: 2011-2014. Rev Chil Obstet Ginecol. 2016, 81:88-96. 10.4067/S0717-75262016000400004

27. Sultana S, Ishtiaque S, Fareed S, Kamal S, Aslam Z, Hussain R, Lashari S: Clinical spectrum of near-miss cases in obstetrics. Cureus. 2019, 11:e4641. 10.7759/cureus.4641

28. Hasbún H J, Sepúlveda-Martínez A, Cornejo R R, Romero P C: [Intensive care admissions due to severe maternal morbidity] [Article in Spanish]. Rev Med Chil. 2013, 141:1512-9. 10.4067/S003498872013001200003

29. David M, Razum O, Henrich W, Ramsauer B, Schlembach D, Breckenkamp J: The impact of migration background on maternal near miss. Arch Gynecol Obstet. 2019, 300:285-92. 10.1007/s00404-019-05179-9

30. Escobar MF, Carvajal JA, Nieto AJ, Messa A, Burgos JM, Echavarria MP, Granados M: Model of obstetric attention based on critical care in Latin America. J Matern Fetal Neonatal Med. 2018, 31:3139-3146. 10.1080/14767058.2017.1365128

31. Soares FM, Pacagnella RC, Tunçalp Ö, Cecatti JG, Vogel JP, Togoobaatar G, Souza JP: Provision of intensive care to severely ill pregnant women is associated with reduced mortality: results from the WHO Multicountry Survey on Maternal and Newborn Health. Int J Gynaecol Obstet. 2020, 150:346-53. 10.1002/ijgo.13241 